\title{
Effects of Solutally Dominant Convection on Physical Vapor Transport for a Mixture of $\mathrm{Hg}_{2} \mathrm{Br}_{2}$ and $\mathrm{Br}_{2}$ under Microgravity Environments
}

\author{
Geug-Tae Kim ${ }^{\dagger}$ and Moo Hyun Kwon* \\ Department of Chemical Engineering, Hannam University, 1646 Yuseong-daero, Yuseong-gu, Daejeon 305-811, Korea \\ *Department of Applied Chemistry, Woosuk University, 443 Samnye-ro, Samnye-eup, Wanju-gun, Jeonbuk 565-701, Korea \\ (Received 16 November 2013; Received in revised form 26 December 2013; accepted 2 January 2014)
}

\begin{abstract}
The convective flow structures in the vapor phase on earth are shown to be single unicellular, indicating the solutally dominant convection is important. These findings reflect that the total molar fluxes show asymmetrical patterns in a viewpoint of interfacial distributions. With decreasing the gravitational level form $1 \mathrm{~g}_{0}$ down to $1.0 \times 10^{-4} \mathrm{~g}_{0}$, the total molar fluxes decay first order exponentially. It is also found that the total molar fluxes decay first order exponentially with increasing the partial pressure of component B, PB (Torr) form 5 Torr up to 400 Torr. Under microgravity environments less than $1 \mathrm{~g}_{0}$, a diffusive-convection mode is dominant and, results in much uniformity in front of the crystal regions in comparisons with a normal gravity acceleration of $1 \mathrm{~g}_{0}$.
\end{abstract}

Key words: Solutally Dominant Convection, Microgravity Environment

\section{INTRODUCTION}

Recently Choubey et al. [1] have characterized (Cd, Zn)Te crystals grown by the multi-tube physical vapor transport (PVT) method, using X-ray diffraction (XRD), infra-red (IR) mapping, photoluminescence (PL), mobility lifetime and current-voltage measurements. They have reported the materials exhibit a resistivity in the $2 \times 10^{9}$ ohm $\mathrm{cm}$ range and planar devices from these materials of $4.07 \times 10^{-3}$ $\mathrm{cm}^{2} \mathrm{~V}^{-1}$ electron mobility. Shi et al. [2] utilized the physical vapor transport technique to prepare $6 \mathrm{H}$-type silicon carbide whiskers and to investigate the mechanism of nucleation and the growth of $\mathrm{SiC}$ whiskers. In the paper, two key factors of (1) the evaporation of raw materials, and (2) the transportation and transition of the vapor species were found. Zotov et al. [3] prepared dense La-Sr-Fe-Co oxgen transport membranes on metal supports deposited by low plasma spraying physical vapor deposition. Fanton et al. [4] dealt with the effect of hydrogen on the properties of $\mathrm{SiC}$ crystals grown by the PVT in view of thermodynamic considerations and experimental results. They showed the level of boron contamination in all samples was not affected by the addition of hydrogen. Su et al. [5] used the self-seeded PVT method in horizontal orientations to prepare $\mathrm{ZnSe}$ crystals. In particular, the effects of convection on the vapor phase within the ampoule during the PVT processes are presented. Paorici et al. [6] have performed the experiments of PVT techniques for urotropine to prove one-dimensional diffusion model to get qualitative results: low mass transport rates of polycrystalline urotropine imply high amounts of volatile impurities.

\footnotetext{
$\dagger$ To whom correspondence should be addressed.

E-mail: geugtaekim@gmail.com

This is an Open-Access article distributed under the terms of the Creative Commons Attribution Non-Commercial License (http://creativecommons.org/licenses/bync/3.0) which permits unrestricted non-commercial use, distribution, and reproducnc/3.0) which permits unrestricted non-commercial use, distribution, tion in any medium, provided the original work is properly cited.
}

Even though the process of PVT is an important crystal growth process in applications for acousto-optic materials [1-6], until now a better and thorough understanding of convection is required as a basis on the ground for space experiments in the future. This motivation causes us to investigate effects of solutally dominant convection on PVT for a mixture of $\mathrm{Hg}_{2} \mathrm{Br}_{2}$ and $\mathrm{Br}_{2}$ under microgravity environments. In particular, the microgravity environments allow the authors to find out the essence of convection. Because space experiments require much expense, such research projects should be generally performed through the aids of various government research consortiums. A mixture of $\mathrm{Hg}_{2} \mathrm{Br}_{2}$ and $\mathrm{Br}_{2}$ is chosen as a systematic model study for further study into microgravity environments. In this study we present the fundamental essence of solutally dominant convection in the PVT processes of $\mathrm{Hg}_{2} \mathrm{Br}_{2}$ crystal growth under the microgravity environments.

\section{ANALYSIS OF SYSTEM}

For analysis of a system, we consider a rectangular enclosure of height $\mathrm{H}$ and transport length $\mathrm{L}$, shown in Fig. 1. The physical and mathematical formulations and many assumptions could be found in Refs. [7-20]. For simplicity, detailed assumptions used in this analysis are not described here. $\mathrm{u}_{x}, \mathrm{u}_{y}$ denote the velocity components along the $\mathrm{x}$ - and $\mathrm{y}$-coordinates in the $\mathrm{x}, \mathrm{y}$ rectangular coordinate, and $\mathrm{T}, \omega_{A}$, $\mathrm{p}$ denote the temperature, mass fraction of species $\mathrm{A}\left(\mathrm{Hg}_{2} \mathrm{Br}_{2}\right)$ and pressure, respectively, where the superscript of * denotes the dimensionless [13-17].

$$
\begin{aligned}
& \nabla^{*} \cdot \overrightarrow{\mathrm{V}}^{*}=0 \\
& \overrightarrow{\mathrm{V}}^{*} \cdot \nabla^{*} \overrightarrow{\mathrm{V}}^{*}=-\nabla^{*} \mathrm{p}^{*}+\operatorname{Pr} \cdot \operatorname{Ar} \nabla^{* 2} \overrightarrow{\mathrm{V}}^{*}-\frac{\mathrm{Ra} \cdot \operatorname{Pr}}{\mathrm{Ar}} \cdot \mathrm{T}^{*} \cdot \mathrm{e}_{g},
\end{aligned}
$$




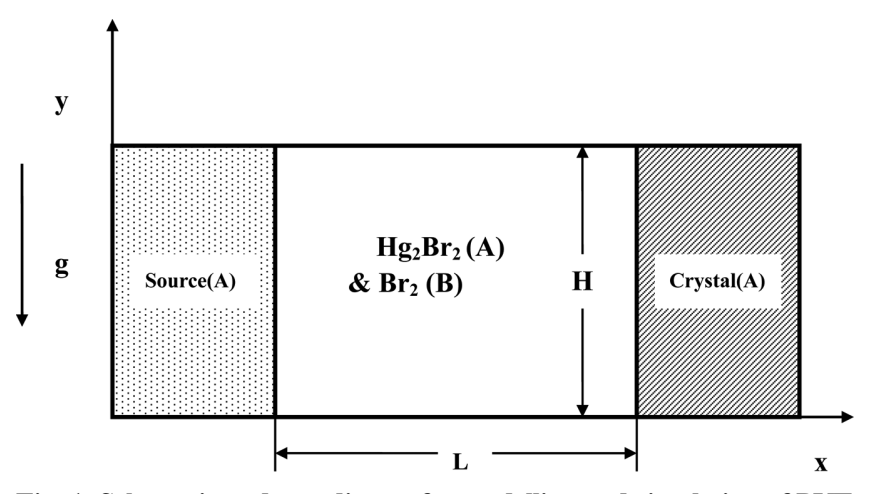

Fig. 1. Schematic and coordinates for modelling and simulation of PVT crystal growth reactor of $\mathrm{Hg}_{2} \mathrm{Br}_{2}(\mathrm{~A})-\mathrm{Br}_{2}(\mathrm{~B})$, adapted from Ref. [7].

$$
\begin{aligned}
& \overrightarrow{\mathrm{V}}^{*} \bullet \nabla^{*} \mathrm{~T}^{*}=\operatorname{Ar} \nabla^{* 2} \mathrm{~T}^{*} \\
& \overrightarrow{\mathrm{V}}^{*} \bullet \nabla^{*} \omega_{A}^{*}=\frac{\operatorname{Ar}}{\mathrm{Le}} \nabla^{* 2} \omega_{A}^{*}
\end{aligned}
$$

On the walls $\left(0<\mathrm{x}^{*}<\mathrm{L} / \mathrm{H}, \mathrm{y}^{*}=0\right.$ and 1$)$ :

$$
\begin{aligned}
& \mathrm{u}^{*}\left(\mathrm{x}^{*}, 0\right)=\mathrm{u}^{*}\left(\mathrm{x}^{*}, 1\right)=\mathrm{v}^{*}\left(\mathrm{x}^{*}, 0\right)=\mathrm{v}^{*}\left(\mathrm{x}^{*}, 1\right)=0 \\
& \frac{\partial \omega_{A}^{*}\left(\mathrm{x}^{*}, 0\right)}{\partial \mathrm{y}^{*}}=\frac{\partial \omega_{A}^{*}\left(\mathrm{x}^{*}, 1\right)}{\partial \mathrm{y}^{*}}=0, \\
& \mathrm{~T}^{*}\left(\mathrm{x}^{*}, 0\right)=\mathrm{T}^{*}\left(\mathrm{x}^{*}, 1\right)=\frac{\mathrm{T}-\mathrm{T}_{c}}{\mathrm{~T}_{s}-\mathrm{T}_{c}}
\end{aligned}
$$

On the source $\left(\mathrm{x}^{*}=0,0<\mathrm{y}^{*}<1\right)$ :

$$
\begin{aligned}
& \mathrm{u}^{*}\left(0, \mathrm{y}^{*}\right)=-\frac{1}{\operatorname{Le}} \frac{\Delta \omega}{\left(1-\omega_{A, s}\right)} \frac{\partial \omega_{A}^{*}\left(0, \mathrm{y}^{*}\right)}{\partial \mathrm{x}^{*}} \\
& \mathrm{v}^{*}\left(0, \mathrm{y}^{*}\right)=0 \\
& \mathrm{~T}^{*}\left(0, \mathrm{y}^{*}\right)=1 \\
& \omega_{A}^{*}\left(0, \mathrm{y}^{*}\right)=1
\end{aligned}
$$

On the crystal $\left(\mathrm{x}^{*}=\mathrm{L} / \mathrm{H}, 0<\mathrm{y}^{*}<1\right)$ :

$$
\begin{aligned}
& \mathrm{u}^{*}\left(\mathrm{~L} / \mathrm{H}, \mathrm{y}^{*}\right)=-\frac{1}{\operatorname{Le}} \frac{\Delta \omega}{\left(1-\omega_{A, c}\right)} \frac{\partial \omega_{A}^{*}\left(\mathrm{~L} / \mathrm{H}, \mathrm{y}^{*}\right)}{\partial \mathrm{x}^{*}} \\
& \mathrm{v}^{*}\left(\mathrm{~L} / \mathrm{H}, \mathrm{y}^{*}\right)=0, \\
& \mathrm{~T}^{*}\left(\mathrm{~L} / \mathrm{H}, \mathrm{y}^{*}\right)=0, \\
& \omega_{A}^{*}\left(\mathrm{~L} / \mathrm{H}, \mathrm{y}^{*}\right)=0,
\end{aligned}
$$

The linear temperature profiles at wall boundary conditions only are considered. It should be emphasized that the finite normal velocities at the interfaces can be expressed by Stefan flow deduced from the one-dimensional diffusion-limited model [21]. The thermo-physical properties and seven dimensionless parameters of solutal Grashof number, thermal Grashof number, aspect ratio, Prandtl number, Lewis number, concentration number, and Peclet number are listed in Table 1. Note that the thermo-physical properties and seven dimensionless parameters are typical operating conditions used in this study. The numerical verifications of our results have been done in Refs. [18-20].

Korean Chem. Eng. Res., Vol. 52, No. 1, February, 2014
Table 1. Typical thermo-physical properties $\left(M_{A}=560.988, M_{B}=159.808\right)$

\begin{tabular}{ll}
\hline \hline Transport length, $\mathrm{L}$ & $10 \mathrm{~cm}$ \\
Height, $\mathrm{H}$ & $2 \mathrm{~cm}$ \\
Source temperature, $\mathrm{T}_{s}$ & $623 \mathrm{~K}$ \\
Crystal temperature, $\mathrm{T}_{c}$ & $533 \mathrm{~K}$ \\
Density of a mixture in the vapor phase, $\rho$ & $0.0031 \mathrm{~g} / \mathrm{cm}^{3}$ \\
Dynamic viscosity, $\mu$ & $0.00033 \mathrm{~g} /(\mathrm{cm} \cdot \mathrm{sec})$ \\
Binary diffusivity, $\mathrm{D}_{A B}$ & $0.17 \mathrm{~cm}^{2} / \mathrm{s}$ \\
Coefficient of thermal expansion, $\beta$ & $0.0016 \mathrm{~K}^{-1}$ \\
Prandtl number, Pr & 0.79 \\
Lewis number, Le & 0.78 \\
Peclet number, Pe & 4.1 \\
Concentration number, $\mathrm{C}_{v}$ & 1.01 \\
Total system pressure, $\mathrm{P}_{T}$ & $430.05 \mathrm{Torr}$ \\
Partial pressure of component B, $\mathrm{P}_{B}$ & $20 \mathrm{Torr}$ \\
Thermal Grashof number, $\mathrm{Gr}_{t}$ & $9.85 \times 10^{4}$ \\
Solutal Grashof number, $\mathrm{Gr}_{s}$ & $6.79 \times 10^{5}$ \\
\hline
\end{tabular}

\section{RESULTS AND DISCUSSION}

Fig. 2 shows the interfacial distributions of molar flux (moles $\mathrm{cm}^{-2} \mathrm{~s}^{-1}$ ) of $\mathrm{Hg}_{2} \mathrm{Br}_{2}$ for two gravity accelerations $\left(\mathrm{gg}_{0}\right.$ and $0.1 \mathrm{~g}_{0}$, where $1 \mathrm{~g}_{0}=$ $\left.981 \mathrm{~cm} \mathrm{~s}^{-2}\right)$, based on $\Delta \mathrm{T}=90 \mathrm{~K}(623 \mathrm{~K} \rightarrow 533 \mathrm{~K}), \mathrm{P}_{B}=20 \mathrm{Torr}, \mathrm{Ar}=$ $5.0, \mathrm{Pr}=0.79, \mathrm{Le}=0.78, \mathrm{Gr}_{t}=9.85 \times 10^{4}, \mathrm{Gr}_{s}=6.79 \times 10^{6}, \mathrm{Pe}=4.1$, $\mathrm{C}_{v}=1.01$. The horizontal orientations and the linear temperature profiles at walls are considered in this study. Here, the subscript of 0 denotes the normal gravity acceleration of $981 \mathrm{~cm} \mathrm{~s}^{-2}$. With decreasing the gravitational acceleration from $1 \mathrm{~g}_{0}$ down to $0.1 \mathrm{~g}_{0}$, the total molar flux for $0.1 \mathrm{~g}_{0}, 1.33 \times 10^{-5}$ moles $\mathrm{cm}^{-2} \mathrm{~s}^{-1}$, is reduced by a factor of 0.61 , in comparison with $1 \mathrm{~g}_{0}, 2.18 \times 10^{-5}$ moles $\mathrm{cm}^{-2} \mathrm{~s}^{-1}$. As depicted

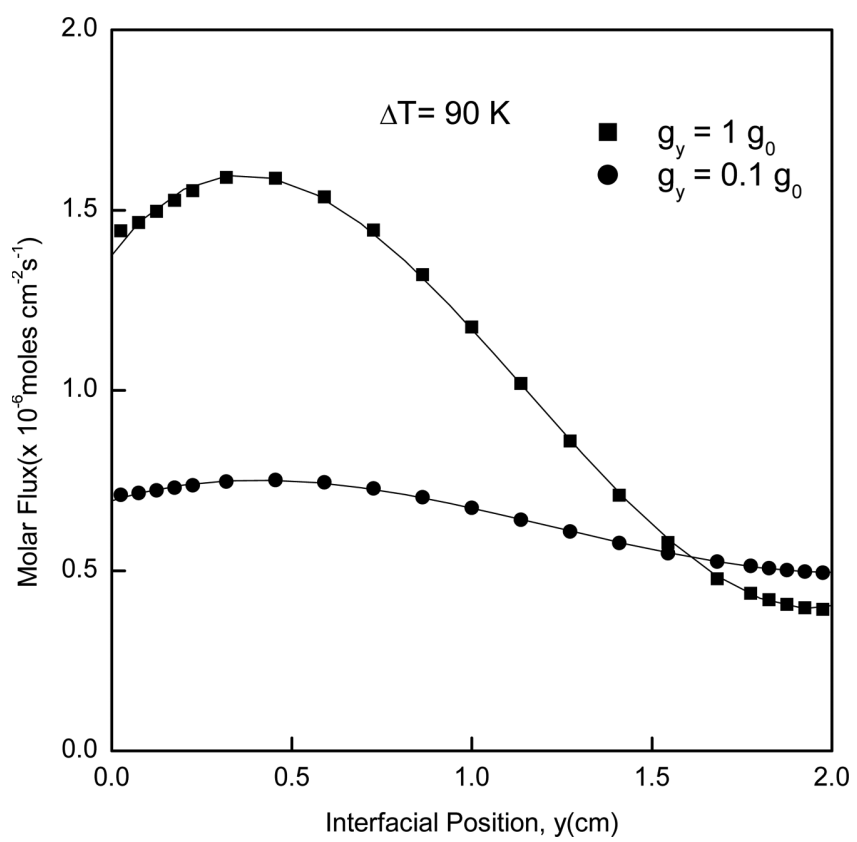

Fig. 2. Interfacial distributions of molar flux (moles $\left.\mathrm{cm}^{-2} \mathrm{~s}^{-1}\right)$ of $\mathrm{Hg}_{2} \mathrm{Br}_{2}$ for two gravity accelerations $\left(1 \mathrm{~g}_{0}\right.$ and $0.1 \mathrm{~g}_{0}$, where $1 \mathrm{~g}_{0}=981$ $\left.\mathrm{cm} \mathrm{s}^{-2}\right)$, based on $\Delta \mathrm{T}=90 \mathrm{~K}(623 \mathrm{~K} \rightarrow 533 \mathrm{~K}), \mathrm{P}_{B}=20$ Torr, $\mathrm{Ar}$ $=5.0, \mathrm{Pr}=0.79, \mathrm{Le}=0.78, \mathrm{Gr}_{t}=9.85 \times 10^{4}, \mathrm{Gr}_{s}=6.79 \times 10^{6}$, $\mathrm{Pe}=$ 4.1, $\mathrm{C}_{v}=1.01$. 
in Fig. 2, similar to the earlier results of Markham et al. [11], one sees that the convective flow can cause significant non-uniformities in the molar flux, with the specific distribution revealing dominance of solutally dominant convection. Even though not shown here, the single convection cell flows towards the growing interface in the lower half of the growth ampoule, thus better supplying this part of the interface with vapor supersaturated in component A. Note that if there is thermal convection alone, with the left part of the ampoule warmer than the right part, an oppositely rotating roll would appear and, thus, result in enhancing the growth of crystal in the upper half of the interface [11]. As shown in Fig. 2, the interfacial distributions of molar flux show asymmetry with respect to $y=1.0 \mathrm{~cm}$, which indicates the presence of asymmetrical convection. Therefore, the asymmetrical convection cell in front of the crystal interface indicates three dimensional flow structures. It is also obvious that from the point of view of the uniformity, the molar flux along the interfacial positions at $\mathrm{g}_{\mathrm{y}}=0.1 \mathrm{~g}_{0}$ exhibits a relatively flat structure compared to that at $\mathrm{g}_{y}=1 \mathrm{~g}_{0}$. It indicates a factor of one tenth reduction in the gravitational level is enough to suppress solutally dominant convective effects on the crystal growth flux.

Fig. 3 shows interfacial distributions of molar flux (moles $\mathrm{cm}^{-2} \mathrm{~s}^{-1}$ ) of $\mathrm{Hg}_{2} \mathrm{Br}_{2}$ for two gravity accelerations $\left(1_{\mathrm{g} 0}\right.$ and $0.1_{\mathrm{g} 0}$, where $1_{\mathrm{g} 0}=$ $\left.981 \mathrm{~cm} \mathrm{~s}^{-2}\right)$, based on $\Delta \mathrm{T}=30 \mathrm{~K}(623 \mathrm{~K} \rightarrow 593 \mathrm{~K}), \mathrm{P}_{B}=20$ Torr, $\mathrm{Ar}=$ 5.0, $\mathrm{Pr}=0.83, \mathrm{Le}=0.44, \mathrm{Gr}_{t}=9.3 \times 10^{4}, \mathrm{Gr}_{s}=9.8 \times 10^{5}, \mathrm{Pe}=3.1, \mathrm{C}_{v}=$ 1.04. In PVT processes, the temperature difference between source and crystal is one of the major parameters as well as a driving force for the mass transport. Under otherwise unchanged process conditions, decreasing the temperature difference for $\mathrm{Ar}=5$ gives similar results to Fig. 2. This suggests that even under the gravity environ-

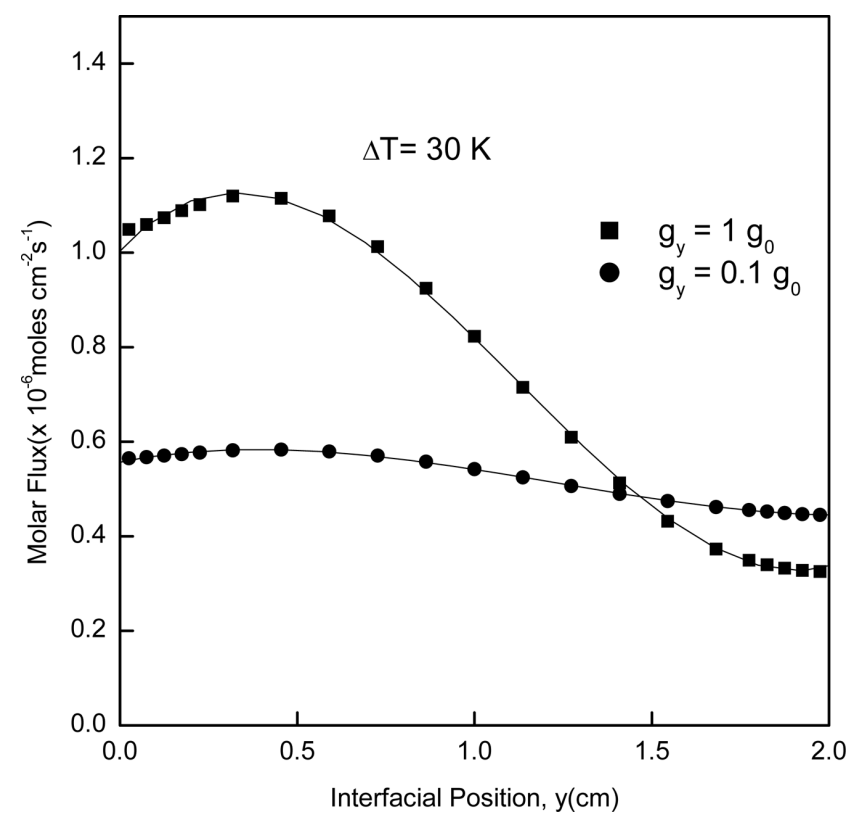

Fig. 3. Interfacial distributions of molar flux (moles $\left.\mathrm{cm}^{-2} \mathrm{~s}^{-1}\right)$ of $\mathrm{Hg}_{2} \mathrm{Br}_{2}$ for two gravity accelerations $\left(1 \mathrm{~g}_{0}\right.$ and $0.1 \mathrm{~g}_{0}$, where $1 \mathrm{~g}_{0}=981$ $\left.\mathrm{cm} \mathrm{s}^{-2}\right)$, based on $\Delta \mathrm{T}=30 \mathrm{~K}(623 \mathrm{~K} \rightarrow 593 \mathrm{~K}), \mathrm{P}_{B}=20$ Torr, Ar $=5.0, \mathrm{Pr}=0.83, \mathrm{Le}=0.44, \mathrm{Gr}_{t}=9.3 \times 10^{4}, \mathrm{Gr}_{s}=9.8 \times 10^{5}, \mathrm{Pe}=$ 3.1, $C_{v}=1.04$. ment of $0.1 \mathrm{~g}_{0}$, the variations in the temperature differences between source and crystal have little effect on the pattern of the molar fluxes in the interfacial distributions (Fig. 2), without the drawback of decreased solutally dominant convection that would result from these measures on ground experiments. Compared with Figs. 2 and 3 , it is clear that the effects of thermally buoyancy driven convection are also important even in reduced gravity environments. The maximum molar flux at $\Delta \mathrm{T}=90 \mathrm{~K}$ reaches at $1.59 \times 10^{-6} \mathrm{moles} \mathrm{cm}^{-2} \mathrm{~s}^{-1}$, and the maximum flux of $1.12 \times 10^{-6}$ moles $\mathrm{cm}^{-2} \mathrm{~s}^{-1}$ is obtained at $\Delta \mathrm{T}$ $=30 \mathrm{~K}$. When the temperature difference is decreased from $623 \mathrm{~K}$ by a factor of 0.33 , i.e., $\Delta \mathrm{T}=90 \mathrm{~K} \rightarrow \Delta \mathrm{T}=30 \mathrm{~K}$, the corresponding maximum molar flux is also decreased from $1.59 \times 10^{-6} \mathrm{moles} \mathrm{cm}^{-2} \mathrm{~s}^{-1}$ by a factor of 0.70 , i.e., $1.59 \times 10^{-6}$ moles cm $\mathrm{cm}^{-2} \mathrm{~s}^{-1} \rightarrow 1.12 \times 10^{-6}$ moles cm $\mathrm{cm}^{-1} \mathrm{~s}^{-1}$. Note that the total molar flux is greater by one order of magnitude than molar flux for both cases of $\Delta \mathrm{T}=90 \mathrm{~K}$ and $30 \mathrm{~K}$.

Fig. 4 shows the effects of partial pressure of component $\mathrm{B}, \mathrm{P}_{B}$ (Torr) on the total molar flux of $\mathrm{Hg}_{2} \mathrm{Br}_{2}$ in terms of moles $\mathrm{cm}^{-2} \mathrm{~s}^{-1}$ for various partial pressures of component $\mathrm{B}, \mathrm{P}_{B}$ (Torr), $5 \mathrm{P}_{B} 400$, based on $\Delta \mathrm{T}=90 \mathrm{~K}(623 \mathrm{~K} \rightarrow 533 \mathrm{~K})$, one gravity acceleration $\left(\lg _{0}\right.$, where $1 \mathrm{~g}_{0}=981 \mathrm{~cm} \mathrm{~s}^{-2}$ ), with the linear temperature profiles at walls. As plotted in Fig. 4, the total molar fluxes decay first order exponentially with the partial pressure of component $\mathrm{B}, \mathrm{P}_{\mathrm{B}}$ (Torr) for 5 Torr $\leq$ $\mathrm{P}_{\mathrm{B}} \leq 400$ Torr. For the range of 5 Torr $\leq \mathrm{P}_{\mathrm{B}} \leq 100$ Torr, the molar fluxes drop significantly, and, for 100 Torr $\leq \mathrm{P}_{B} \leq 400$ Torr, decreases slowly. In other words, the total molar fluxes decrease much sharply near $\mathrm{P}_{B}=5$ Torr, and, then since $\mathrm{P}_{B}=100$ Torr, decrease slowly until at $\mathrm{P}_{B}=400$ Torr. Moreover, as the $\mathrm{P}_{B}$ is increased from 100 Torr to 400 Torr, i.e. by a factor of 4 , and the total molar flux is decreased from $1.37 \times 10^{-5}$ moles $\mathrm{cm}^{-2} \mathrm{~s}^{-1}$ down to $7.53 \times 10^{-6}$ moles $\mathrm{cm}^{-2} \mathrm{~s}^{-1}$ by

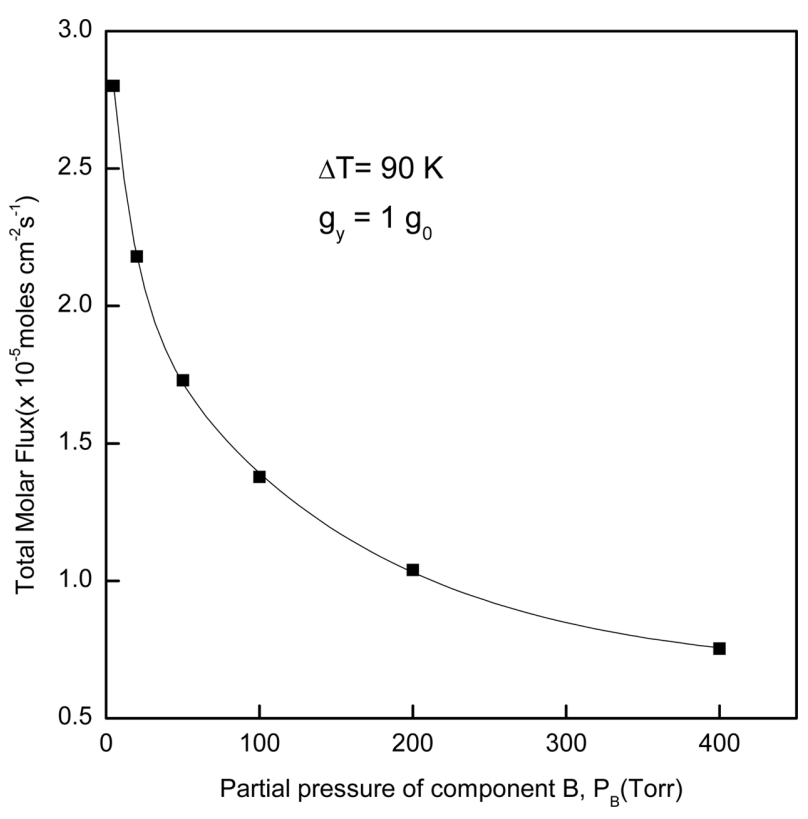

Fig. 4. Effects of partial pressure of component $B, P_{B}$ (Torr) on the total molar flux of $\mathrm{Hg}_{2} \mathrm{Br}_{2}$ in terms of moles $\mathrm{cm}^{-2} \mathrm{~s}^{-1}$ for various partial pressures of component $B, P_{B}$ (Torr), 5 Torr $P_{B}$ 400 Torr, based on $\Delta \mathrm{T}=90 \mathrm{~K}(623 \mathrm{~K} \rightarrow 533 \mathrm{~K})$, one gravity accelerations $\left(1 \mathrm{~g}_{0}\right.$, where $\left.1 \mathrm{~g}_{0}=981 \mathrm{~cm} \mathrm{~s}^{-2}\right)$.

Korean Chem. Eng. Res., Vol. 52, No. 1, February, 2014 


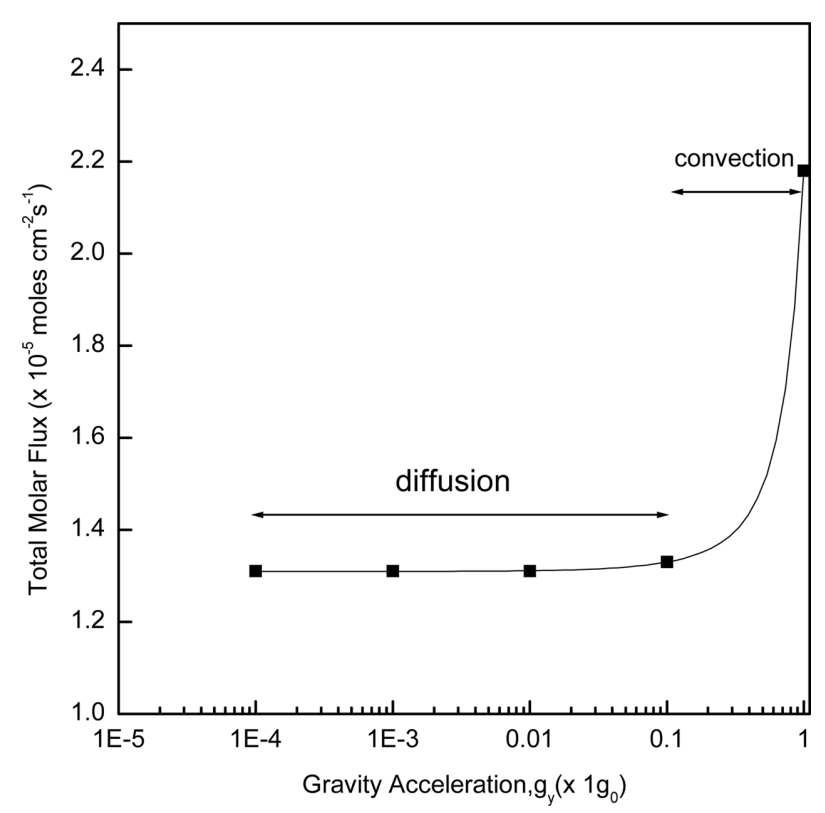

Fig. 5. Total molar flux of $\mathrm{Hg}_{2} \mathrm{Br}_{2}$ in terms of moles $\mathrm{cm}^{-2} \mathrm{~s}^{-1}$ as a function of gravity accelerations, $10^{-4} \mathrm{~g}_{0}$ gy $1 \mathrm{~g}_{0}$, based on $\mathrm{P}_{B}=\mathbf{2 0}$ Torr and $\Delta \mathrm{T}=90 \mathrm{~K}(623 \mathrm{~K} \rightarrow 533 \mathrm{~K})$.

a factor of 0.54. On the other hand, as the $\mathrm{P}_{\mathrm{B}}$ is increased from 20 Torr to 100 Torr, i.e. by a factor of 5 , and the total molar flux is decreased from $2.18 \times 10^{-5}$ moles $\mathrm{cm}^{-2} \mathrm{~s}^{-1}$ down to $1.37 \times 10^{-5}$ moles $\mathrm{cm}^{-2} \mathrm{~s}^{-1}$ by a factor of 0.62 . Consequently, the factor of decrease in the total molar flux for 20 Torr $\leq \mathrm{P}_{B} \leq 100$ Torr, i.e., 0.62 is approximately same as for 100 Torr $\leq \mathrm{P}_{\mathrm{B}} \leq 400$ Torr, i.e., 0.54 , considering the factor of increase in the partial pressure of component $\mathrm{B}, \mathrm{P}_{B}$ (Torr).

Fig. 5 shows the total molar flux of $\mathrm{Hg}_{2} \mathrm{Br}_{2}$ in terms of moles $\mathrm{cm}^{-2} \mathrm{~s}^{-1}$ as a function of gravity acceleration, $10^{-4} \mathrm{~g}_{0} \leq \mathrm{g}_{y} \leq 1 \mathrm{~g}_{0}$, based on $\mathrm{P}_{B}$ $=20$ Torr and $\Delta \mathrm{T}=90 \mathrm{~K}$. The solutally dominant convection mode is predominant over the diffusion mode for $10^{-1} \mathrm{~g}_{0} \leq \mathrm{gy} \leq 1 \mathrm{~g}_{0}$. The solutally dominant convection mode is transited into the diffusion mode at $g_{y}=0.1 g_{0}$ and, since $g_{y}=0.1 g_{0}$, down to $g_{y}=10^{-4} \mathrm{~g}_{0}$, the diffusion becomes predominant. As seen in Fig. 5, the total molar fluxes drop sharply for $10^{-1} \mathrm{~g}_{0} \leq \mathrm{gy} \leq 1 \mathrm{~g}_{0}$. This indicates the mass transport is diffusion-dominated under the microgravity environments less than $0.1 \mathrm{~g}_{0}$. One can see that the effect of solutally dominant convection is first important and then decreases rapidly and eventually the mode of transport becomes largely diffusion. Therefore, the gravitational parameter is significantly important, which gives us deep motivations to perform numerical studies under microgravity environments.

Fig. 6 shows the interfacial distributions of total molar flux (moles $\mathrm{cm}^{-2} \mathrm{~s}^{-1}$ ) of $\mathrm{Hg}_{2} \mathrm{Br}_{2}$ for various molecular weight of component $\mathrm{B}$, $\mathrm{M}_{B}, 2 \leq \mathrm{M}_{B} \leq 159$, based on $\mathrm{Ar}=5$ Torr and $\Delta \mathrm{T}=90 \mathrm{~K}$. One also investigated situations when thermal convection might dominate solutal convection. This could occur when an inert gas having a molecular weight $\mathrm{M}_{B}$ closer to that of the crystallizing material is used. With varying molecular weight of component $B$ from 2 up to 400 , one can see that the effect of solutal convection decreases rapidly for $2 \leq \mathrm{M}_{B}$

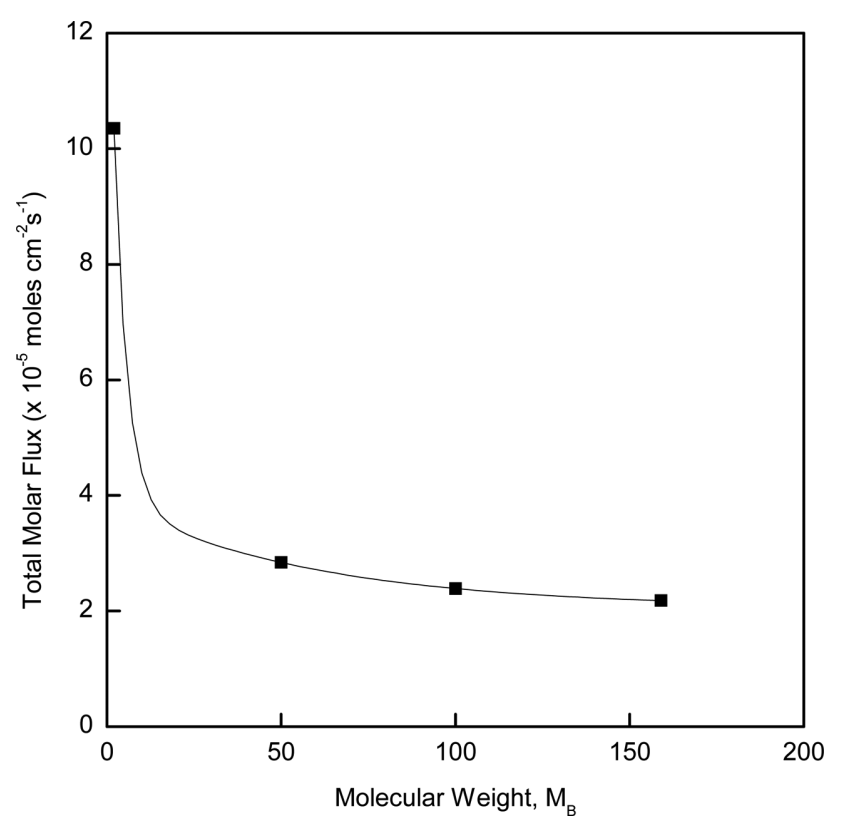

Fig. 6. Total molar flux (moles $\left.\mathrm{cm}^{-2} \mathrm{~s}^{-1}\right)$ of $\mathrm{Hg}_{2} \mathrm{Br}_{2}$ for various molecular weight of component $B, M B, 2 \leq M_{B} \leq 159$, based on Ar $=5$ and $\Delta \mathrm{T}=90 \mathrm{~K}(623 \mathrm{~K} \rightarrow 533 \mathrm{~K})$.

$\leq 50$, and, for $50 \leq \mathrm{M}_{B} \leq 159$, eventually the transport becomes largely diffusive. For conditions under consideration, note that only when the molecular weights of $\mathrm{A}$ and $\mathrm{B}$ are equal does the thermal density gradient overcome the solutal gradient. It is concluded that unless the two components have molecular weights very close to each other, the dominant mode of convection is likely to be solutal. It is emphasized that the effects of solutally dominant convection are reflected through the density gradient and binary diffusivity coefficient. The maximum molar fluxes occur in the main in the neighborhood of $y=$

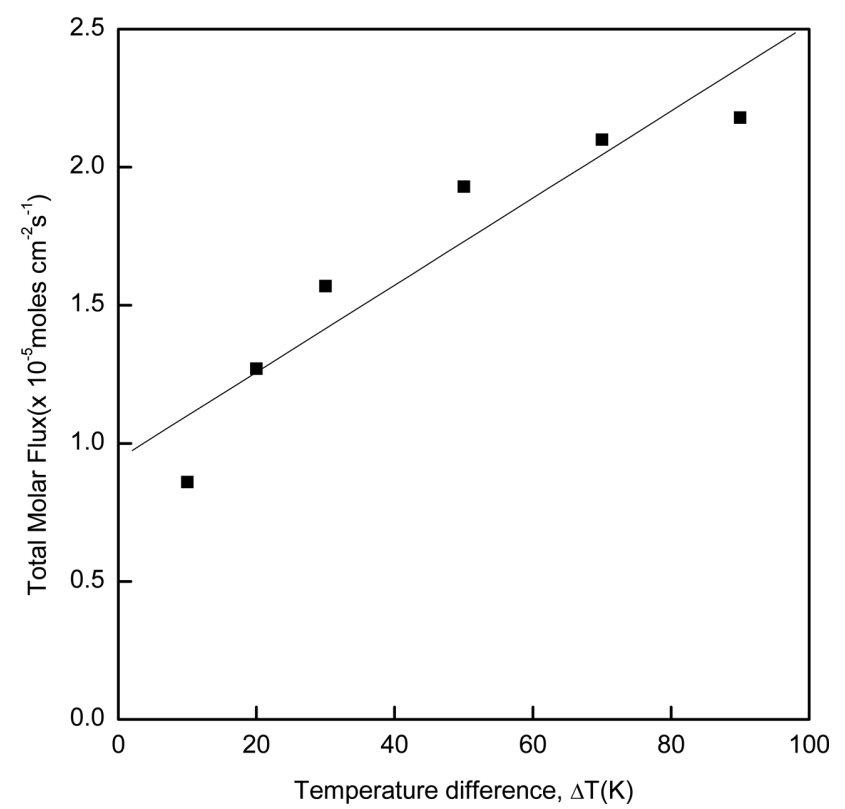

Fig. 7. Relationship between total molar flux (moles $\mathrm{cm}^{-2} \mathrm{~s}^{-1}$ ) of $\mathrm{Hg}_{2} \mathrm{Br}_{2}$ and the temperature difference between the source and the crystal regions, 10 Torr $\leq \Delta \mathrm{T} \leq 90 \mathrm{~K}$, based on $\mathrm{Ar}=5$ and $\mathrm{P}_{B}$ $=20$ Torr. 
(a) Velocity profile

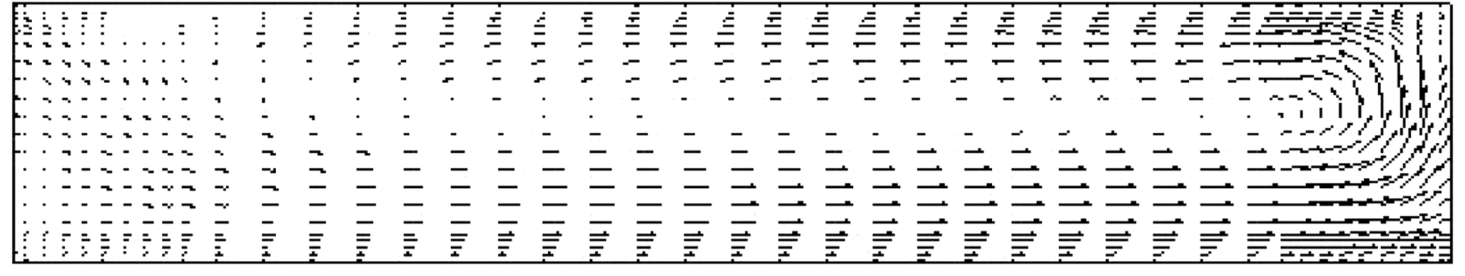

(b) Temperature profile

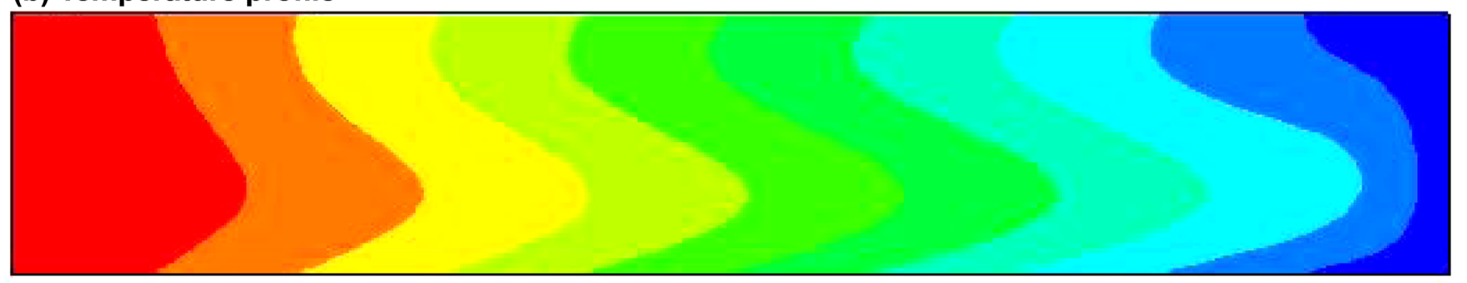

\section{(c) Concentration profile}
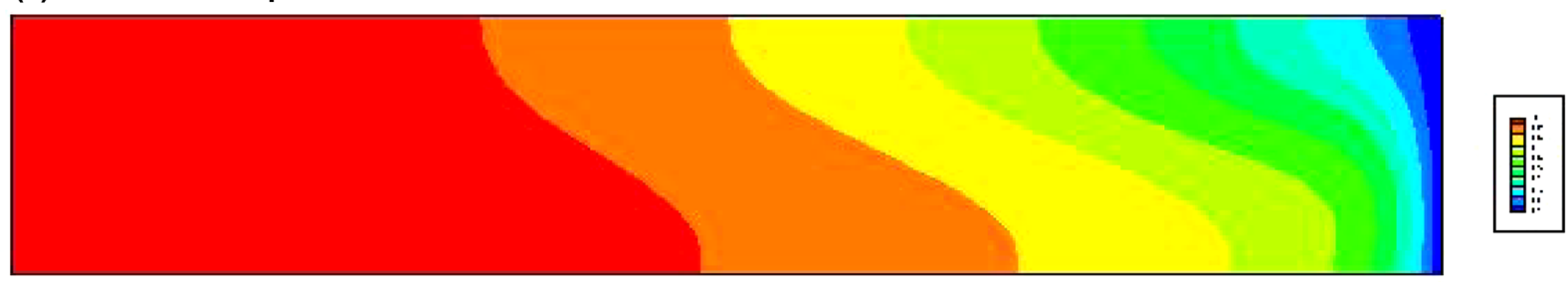

Fig. 8. (a) Velocity profile, (b) temperature profile, (c) concentration profile, based on $\Delta T=80 \mathrm{~K}(623 \mathrm{~K} \rightarrow 543 \mathrm{~K})$, and $1 \mathrm{~g} \mathrm{~g}_{0}$. A relative velocity vector with 50 magnitudes has $0.3 \mathrm{~cm}$. The dimensional maximum magnitude of velocity vector is $0.76 \mathrm{~cm} \mathrm{~s}^{-1}$.

\section{5 , not shown here.}

Fig. 7 shows the relationship between total molar flux (moles $\left.\mathrm{cm}^{-2} \mathrm{~s}^{-1}\right)$ of $\mathrm{Hg}_{2} \mathrm{Br}_{2}$ and the temperature difference between the source and the crystal regions, $10 \mathrm{~K} \leq \Delta \mathrm{T} \leq 90 \mathrm{~K}$, based on $\mathrm{Ar}=5$ and $\mathrm{P}_{B}=20$ Torr. As shown in Fig. 7, the total molar flux of $\mathrm{Hg}_{2} \mathrm{Br}_{2}$ for various temperature difference between the source and the crystal regions, 10 $\mathrm{K} \leq \Delta \mathrm{T} \leq 90 \mathrm{~K}$, has a direct and linearly relationship with the temperature difference, $\Delta \mathrm{T}$. For $10 \mathrm{~K} \leq \Delta \mathrm{T} \leq 30 \mathrm{~K}$, the total molar flux is significantly dependent on the temperature difference, while for $50 \mathrm{~K} \leq$ $\Delta \mathrm{T} \leq 90 \mathrm{~K}$, it varies slightly with the temperature difference. The temperature gradient for $10 \mathrm{~K} \leq \Delta \mathrm{T} \leq 30 \mathrm{~K}$ is, 0.0355 moles cm $\mathrm{cm}^{-1} \mathrm{~S}^{-1}$ and $0.00625 \mathrm{moles} \mathrm{cm}^{-2} \mathrm{~s}^{-1} \mathrm{~K}^{-1}$ for $50 \mathrm{~K} \leq \Delta \mathrm{T} \leq 90 \mathrm{~K}$. Therefore, the temperature gradient for $10 \mathrm{~K} \leq \Delta \mathrm{T} \leq 30 \mathrm{~K}$ is greater than for $50 \mathrm{~K}$ $\leq \Delta \mathrm{T} \leq 90 \mathrm{~K}$ by a factor of 5.68 . This reflects an increase in the intensity of thermally buoyancy driven convection with increasing the driving force of crystal growth, i.e., the temperature difference.

In order to get a deep understanding and further insight into the essence of solutally dominant convection in the vapor phase during the PVT processes of $\mathrm{Hg}_{2} \mathrm{Br}_{2}$, the velocity vector, temperature, and concentration profiles are shown in Fig. 8. The single cellular convective cell occurs in the vapor phase due to density gradients from unequal molecular weights of $\mathrm{A}$ and $\mathrm{B}$, associated with gravitational acceleration on earth. As shown in Fig. 8(a), the magnitudes of velocity vector near the source region are shown to be greater than those near the crystal region. The unicellular convective structure implies three dimensional convective flow structures. The magnitudes of velocity vector in the lower half region are greater than those in the upper half region along the centerline, dimensionless $\mathrm{y}^{*}=0.5$, i.e., $\mathrm{y}=1 \mathrm{~cm}$, which indicates a strong convective structure under operating conditions of $\Delta \mathrm{T}=80 \mathrm{~K}(623 \mathrm{~K} \rightarrow 543 \mathrm{~K})$, and $1 \mathrm{~g}_{0}, \mathrm{P}_{B}=20 \mathrm{Torr}, \mathrm{Ar}=5.0$, $\mathrm{Pr}=0.80, \mathrm{Le}=0.69, \mathrm{Gr}_{t}=9.57 \times 10^{4}, \mathrm{Gr}_{s}=7.69 \times 10^{5}, \mathrm{Pe}=3.96, \mathrm{C}_{v}=$ 1.01 , thermal diffusivity of $0.11 \mathrm{~cm}^{2} \mathrm{~s}^{-1}$, kinematic viscosity of 0.095 $\mathrm{cm}^{2} \mathrm{~s}^{-1}$, binary diffusivity of $0.17 \mathrm{~cm}^{2} \mathrm{~s}^{-1}$. The temperature profile along the centerline of dimensionless $\mathrm{y}^{*}=0.5$, i.e., $\mathrm{y}=1 \mathrm{~cm}$ exhibits symmetry, indicating a uniform imposed temperature profile on ampoule walls. As shown in Fig. 8(c), with regards to concentration profile, the concentrations in front of the source regions are uniform, and significantly varied near the crystal regions. A relative velocity vector with 50 magnitudes has $0.3 \mathrm{~cm}$. The dimensionless maximum magnitude of velocity vector is 63.5 , and the corresponding dimensional maximum magnitude of velocity vector is $0.76 \mathrm{~cm} \mathrm{~s}^{-1}$.

\section{CONCLUSIONS}

It is concluded that the solutally dominant convection during the physical vapor transport of $\mathrm{Hg}_{2} \mathrm{Br}_{2}-\mathrm{Br}_{2}$ appears to be predominant over the diffusive transport for near normal gravity acceleration levels more than $0.1 \mathrm{~g}_{0}$. The single asymmetrical unicellular convection indicates three dimensional flow structures, and the variations in convective flow structures are significantly important near the crystal regions than the source regions. In particular, from the point of view of the uniformity, such convective flow structures are associ- 
ated with the total molar flux along the crystal interfacial positions. Unless the two components have molecular weights very close to each other, it is concluded that for $2 \leq \mathrm{M}_{B} \leq 50$, the dominant mode of convection is solutal. For the range of 5 Torr $\leq \mathrm{P}_{B} \leq 100$ Torr, the molar fluxes drop significantly, and, for 100 Torr $\leq \mathrm{P}_{B} \leq 400$ Torr, decreases slowly, and, for 5 Torr $\leq \mathrm{P}_{B} \leq 400$ Torr, the total molar fluxes decay first order exponentially with the partial pressure of component $\mathrm{B}, \mathrm{PB}$.

\section{ACKNOWLEDGEMENT}

This work was financially supported by the Hannam University under Grant No. 2013A087 (April 1, 2013 through March 31, 2014).

\section{REFERENCES}

1. Choubey, A., Veeramani, P., Pym, A. T. G., Mullins, J. T., Sellin, P. J., Brinkman, A. W., Radley, I., Basu, A. and Tanner, B. K., "Growth by the Multi-tube Physical Vapour Transport Method and Characterization of Bulk (Cd, Zn)Te,' J. Cryst. Growth, 352, 120-123(2012).

2. Shi, Y., Yang, J. F., Liu, H., Dai, P., Liu, B., Jin, Z., Qiao, G. and Li, H., "Fabrication and Mechanism of 6H-type Silicon Carbide Whiskers by Physical Vapor Transport Technique,', J. Cryst. Growth, 349, 68-74(2012).

3. Zotov, N., Baumann, S., Meulenberg, W. A. and Vaßen, R., "LaSr-Fe-Co Oxygen Transport Membranes on Metal Supports Deposited by Low Pressure Plasma Spraying-Physical Vapour Deposition,' J. Membr. Sci., 442, 119-123(2013).

4. Fanton, M. A., Li, Q., Polyakov, A. Y., Skowronski, M., Cavalero, R. and Ray, R., "Effects of Hydrogen on the Properties of SiC Crystals Grown by Physical Vapor Transport: Thermodynamic Considerations and Experimental Results,' J. Cryst. Growth, 287, 339-343(2006).

5. Su, C. H., George, M. A., Palosz, W., Feth, S. and Lehoczky, S. L., "Contactless Growth of ZnSe Single Crystals by Physical Vapor Transport,' J. Cryst. Growth, 213, 267-275(2000).

6. Paorici, C., Razzetti, C., Zha, M., Zanotti, L., Carotenuto, L. and Ceglia, M., "Physical Vapour Transport of Urotropine: One-Dimensional Model,' Mater. Chem. Phys., 66, 132-137(2000).

7. Lee, Y. K. and Kim, G. T., "Effects of Convection on Physical Vapor Transport of $\mathrm{Hg}_{2} \mathrm{Cl}_{2}$ in the Presence of $\mathrm{Kr}$ - Part I: Under Microgravity Environments,' J. Korean Crystal Growth and Crystal Tech., 23, 20-26(2013).

8. Greenwell, D. W., Markham, B. L. and Rosenberger, F., "Numeri- cal Modeling of Diffusive Physical Vapor Transport in Cylindrical Ampoules,' J. Cryst. Growth, 51, 413-425(1981).

9. Markham, B. L., Greenwell, D. W. and Rosenberger, F., "Numerical Modeling of Diffusive-Convective Physical Vapor Transport in Cylindrical Vertical Ampoules,' J. Cryst. Growth, 51, 426-437 (1981).

10. Jhaveri, B. S. and Rosenberger, F., "Expansive Convection in Vapor Transport across Horizontal Enclosures,' J. Cryst. Growth, 57, 57-64(1982).

11. Markham, B. L. and Rosenberger, F., "Diffusive-Convective Vapor Transport across Horizontal and Inclined Rectangular Enclosures,' J. Cryst. Growth, 67, 241-254(1984).

12. Nadarajah, A., Rosenberger, F. and Alexander, J., "Effects of Buoyancy-Driven Flow and Thermal Boundary Conditions on Physical Vapor Transport,' J. Cryst. Growth, 118, 49-59(1992).

13. Zhou, H., Zebib, A., Trivedi, S. and Duval, W. M. B., "Physical Vapor Transport of Zinc-Telluride by Dissociative Sublimation,' J. Cryst. Growth, 167, 534-542(1996).

14. Duval, W. M. B., "Convective Effects during the Physical Vapor Transport Process-I: Thermal Convection,' J. Mater. Proc. Manufacturing Sci., 1, 83-104(1992).

15. Duval, W. M. B., "Convective Effects during the Physical Vapor Transport Process-II: Thermosolutal Convection,' J. Mater. Proc. Manufacturing Sci., 1, 295-313(1993).

16. Duval, W. M. B., Glicksman, N. E. and Singh, B., "Physical Vapor Transport of Mercurous Chloride Crystals; Design of a Microgravity Experiment,' J. Cryst. Growth, 174, 120-129(1997).

17. Tebbe, P. A., Loyalka, S. K. and Duval, W. M. B., "Finite Element Modeling of Asymmetric and Transient Flow Fields during Physical Vapor Transport,' Finite Elements in Analysis and Design, 40, 1499-1519(2004).

18. Kim, G. T., Duval, W. M. B., Singh, N. B. and Glickman, M. E., "Thermal Convective Effects on Physical Vapor Transport Growth of Mercurous Chloride Crystals $\left(\mathrm{Hg}_{2} \mathrm{Cl}_{2}\right)$ for Axisymmetric 2-D Cylindrical Enclosure,' Model. Simul. Mater. Sci. Eng., 3, 331357(1995).

19. Kim, G. T., Duval, W. M. B. and Glickman, M. E., "Thermal Convection in Physical Vapour Transport of Mercurous Chloride $\left(\mathrm{Hg}_{2} \mathrm{Cl}_{2}\right)$ for Rectangular Enclosures,' Model. Simul. Mater. Sci. Eng., 5, 289-309(1997).

20. Kim, G. T., Duval, W. M. B. and Glickman, M. E., "Effects of Asymmetric Temperature Profiles on Thermal Convection during Physical Vapor Transport of $\mathrm{Hg}_{2} \mathrm{Cl}_{2}$, Chem. Eng. Comm., 162, $45-61$ (1997).

21. Rosenberger, F. and Müller, G., "Interfacial Transport in Crystal Growth, a Parameter Comparison of Convective Effects,' J. Cryst. Growth, 65, 91-104(1983). 